Running head: DEFINING HABIT IN PSYCHOLOGY

\title{
Defining Habit in Psychology
}

Asaf Mazar and Wendy Wood

University of Southern California

Chapter to appear in Verplanken, B. (Ed.), The psychology of habit. 


\title{
DEFINING HABIT IN PSYCHOLOGY
}

\begin{abstract}
We review definitions of habit and evaluate how well current measures capture these definitions. Habits are context-behavior associations in memory that develop as people repeatedly experience rewards for a given action in a given context. Habitual behavior is cued directly by context and does not require supporting goals and conscious intentions. As we explain, goals are important to initiate behavior repetition and to inhibit unwanted habit performance, and in addition can be inferred from habits. To date, research has relied on selfreport methods to measure habit. These measures, by themselves, may fall short of adequately testing key features of habit, such as context dependence, or dissociating habitual and nonhabitual influences on behavior. By augmenting self-reports with implicit, behavioral, and ecological momentary assessment methods, researchers can gain a more complete understanding of habits and their role in shaping behavior.
\end{abstract}

Keywords: habit, automaticlimplicit processes, habit definition, habit measurement. 


\section{DEFINING HABIT IN PSYCHOLOGY}

\section{Defining Habit in Psychology}

We've all said, "I can’t help it, it's just a habit." Colloquially, habits can be convenient excuses for actions that are not ideal. Research into folk explanations shows that people tend to forgive others for misfortunate events when they could be produced by habit (Gershman, Gerstenberg, Baker, \& Cushman, 2016). In one study, participants read a scenario about a problematic office door knob that locked when turned in the wrong direction. Despite being warned, a new worker haplessly did just that during his first day on the job, and locked a colleague into the office for several hours. But he wasn't always blamed. When the scenario noted that his door knobs at home worked in the same direction as the problem one in the office, participants were inclined to forgive. We understand, habits can run off without intention or thought. They are different from other actions. Without the excuse of doorknobs at home turning in that direction, the new worker was held more responsible for the mistake.

Folk psychology is self-serving when it comes to explaining our own habits. We no longer recognize the lack of intention and thought when it comes to our own behavior. In fact, for beneficial actions, people are more likely to claim agency and responsibility for stronger habits. For example, students with strong habits to take the bus or strong habits to watch TV news reported being more certain of their intentions to do these things than students with weaker habits (Ji \& Wood, 2007). Despite this conviction, strong habit participants did not act on their intentions during the next week. Instead, they continued to take the bus or watch the news in a habitual way, regardless of their intentions. For those with weak habits, however, more favorable intentions meant more frequent actions (see also Neal, Wood, Labrecque, \& Lally, 2012). In a way, it makes sense to take credit for beneficial habits, given that they are aligned with intentions. However, intentions do not play a causal role in activating habits.

Folk psychology thus flexibly interprets habit intentionality. It excuses unwanted 


\section{DEFINING HABIT IN PSYCHOLOGY}

habits and claims responsibility for beneficial ones. It fails to reveal, however, the nature of habit. We know the feeling of making a decision, desiring something to happen, and controlling our actions so that it occurs. However, we can't introspect in the same way into the mechanics of habit performance. Like automaticity in general, habits are brought to mind by cognitive processes largely outside of conscious awareness. We can observe the action that results, but we are blind to the mechanism. Recent research is beginning to shed light on exactly what these processes involve.

Unraveling habit processes is the exciting premise of this edited volume. We begin to address this in the present chapter by outlining the history of habit in psychology, focusing especially on the various definitions of habit over the past 150 years of research. To provide an initial framework to the discussion, we note that most modern research begins with a conceptual definition of habits as cue-response associations in memory that are acquired slowly through repetition of an action in a stable circumstance (Gardner, 2015; Orbell \& Verplanken, 2010; Wood \& Rünger, 2016). As we will see, this definition is a relatively recent development in the history of habit, and it opens up many possibilities for habit measurement.

\section{Historic Definitions of Habit}

William James (1916/1983) was a big believer in habit. This is easily seen in his enthusiastic assessment that " $99 \%$, or, possibly, $99.9 \%$ of our activity is purely automatic and habitual, from our rising in the morning to our lying down each night. Our dressing and undressing, our eating and drinking, our greetings and partings...even most of the forms of our common speech, are things of a type so fixed by repetition as almost to be classed as reflex actions" (p. 48).

This enthusiasm set the stage for $20^{\text {th }}$ century research on habit. Early on, researchers highlighted the ways animals and humans learn stimulus-response associations (e.g., 


\section{DEFINING HABIT IN PSYCHOLOGY}

Thorndike, 1898). These ideas formed the foundations of behaviorism, especially radical behaviorism's infamous denial that thoughts and feelings guide action (e.g., Skinner, 1938). Although behaviorism took many forms, a common assumption was that stimuli, rewards, and other external forces guide repeated behavior. (e.g., Hull, 1943).

This early heyday of habit research did not last long. Observing his rats run mazes, Tolman (1948) argued that they formed internal representations and cognitive maps. This theme resonated with psychology's developing interest in the mind. During the cognitive revolution in the mid-century, stimulus-response connections were replaced by informationprocessing models of goal pursuit (e.g., Miller, Galanter, \& Pribram, 1960). In the cognitive view, people act by making decisions and pursuing goals. These ideas were encapsulated in an influential model of behavior prediction - the theory of reasoned action/planned behavior (Fishbein \& Ajzen, 1975, 2011). All actions supposedly reflect people's intentions to act, which were assessed through their explicit ratings of behavioral goals and expectations.

Yet habit did not completely disappear. Triandis $(1977,1980)$ proposed an alternative model, the theory of interpersonal behavior, which recognized that people could act out of habit, repeating past behavior, as well as out of intention (which Triandis likened to selfinstruction). The relative weighting of habit and intention depended on how often people had repeated a behavior in the past. Well-established, overlearned behaviors were repeated without much input from conscious intentions. Triandis's ideas about the relation between habit and conscious decisions were surprisingly modern, predating dual systems models of information processing (Evans \& Stanovich, 2013; Sherman, Gawronski, \& Trope, 2014).

Even the cognitive revolution kept bumping up against habit. When performing a laboratory task in which the same stimuli were presented again and again, people seemed to just repeat the practiced response. They did not experience active control, they could perform secondary tasks, and they did not have to allocate attention (Shiffrin \& Schneider, 1977). 


\section{DEFINING HABIT IN PSYCHOLOGY}

Apparently, they were guided by "a learned sequence of elements in long-term memory initiated by consistent stimuli" (Shiffrin \& Schneider, 1977, p. 1). This habit-like responding was contrasted with controlled processing that involved "temporary activation of a sequence of elements" (p. 1). In this way, habit peaked its nose under the cognitive tent with a new label, automaticity. As we will explain, automaticity proved to be a broad construct with many facets, only some of which correspond to habit. However, early observations of automaticity that emerged from repeated responding to consistent stimuli are closely aligned with habit formation (e.g., Gardner, 2015; Wood \& Rünger, 2016).

Additional impetus for recognizing habit came from cognitive neuroscience. Research revealed that the procedural learning of habit activated somewhat different neural networks than other forms of implicit memory (Squire \& Zola-Morgan, 1991). For habit learning, greater task repetition speeds performance, reduces thought and attention, and increases activation in certain brain regions (Knowlton \& Patterson, 2016). Initially, task performance involves activation in a neural system known as the associative loop. This includes a part of the basal ganglia, the caudate, along with the midbrain and the prefrontal cortex, which is a brain region associated with self-control, planning, and abstract thought. With practice, activation increases in neural networks that include the sensorimotor loop, which connects the putamen of the basal ganglia with the sensorimotor cortices and parts of the midbrain (Tricomi, Balleine, \& O’Doherty, 2009; Yin \& Knowlton, 2006).

The multiple sources of evidence for habit in behavior prediction, cognitive experiments, and neuroscience all pushed researchers in the same direction. Habit could no longer be ignored or replaced with other constructs. Recently, habit has been integrated with sophisticated models of deliberate, thoughtful action (Evans \& Stanovich, 2013). In this synthesis, habit is one of many mechanisms that guide action. It is a category of System 1, defined broadly as cognitive processing that makes minimal demands on working memory. 


\section{DEFINING HABIT IN PSYCHOLOGY}

System 2, in contrast, draws on executive functions that can change or inhibit a faster, default, System 1 response.

The recognition of multiple types of processing is consistent with episode-sampling research tracking the role of thought in guiding action (Wood, Quinn, \& Kashy, 2002). In studies in which participants reported every hour what they were thinking and doing, about $43 \%$ of everyday actions were habitual, in the sense that they were repeated almost every day in the same context and usually performed while people were thinking of something else. Although this estimate falls short of William James's (1916/1983) enthusiastic claims, he was correct in classifying a wide range of actions as habitual, including entertainment, work and study, social interactions, and standard routines of grooming, sleeping, and eating. As he anticipated, a great deal of everyday life is infused with habit automaticity.

Along with the emerging evidence of habitual responding in studies of behavior prediction, cognitive psychology, and neuroscience, psychology has additional reason to embrace habit at this point in time. In the last decade, it is becoming clear that the standard approach to changing behavior is falling short (Wood \& Neal, 2016). People change their behavior temporarily when they are motivated to do so by payment or other rewards (Mantzari et al., 2015). Increased knowledge and information can also change behavior in the short term. Once behavior change interventions end, however, people's motivation wanes, knowledge becomes less salient, and they revert back to what they were doing in the past. Psychology needs new approaches to understand and change behavior.

\section{Modern Definitions}

The cue-response associations of habit memory form as part of instrumental learning, as people repeat behaviors and get rewards in a stable context (Gardner, 2015; Wood \& Rünger, 2016). At first, people might act on their intentions, trying to achieve a goal or attain a desired outcome. As they repeat actions, stable elements in the performance context become 


\section{DEFINING HABIT IN PSYCHOLOGY}

associated with the behavior. Eventually, perception of those elements then can trigger the behavior directly, without a need for a conscious goal representation. For example, a habit of snacking at work may begin as a goal-directed behavior aimed to reduce hunger. Given sufficient repetition, context cues (for example, the sight of one's office) may come to activate the snacking behavior automatically, even in the absence of hunger. Indeed, for people who snack frequently in similar contexts (but not people who snack frequently in varying contexts), intentions do not predict snacking behavior (Danner, Aarts, \& de Vries, 2008). Thus, habit formation is a process by which behavioral control shifts from goal dependence to context dependence. Indeed, a common approach for assessing habitual behavior is measuring its dependence on context cues, along with its independence from goals (see "Habit Measurement" section below).

In this account, many habits begin with goal pursuit. This is one way that habits interface with goals (see also de Wit \& Dickinson, 2009). Wood and Rünger (2016) outlined three ways that goals can be involved in habit performance. First, goals influence habit formation by driving people to repeat actions in a certain context. Thus, goals may energize habit formation by bringing about context-consistent repetition. Second, goals interact with habits by influencing the expression of habitual behavior. Once habits are formed, habitual behaviors are activated in memory directly by context, regardless of goals. However, when people are sufficiently motivated, they might inhibit an unwanted habit, despite it being active in mind. Alternatively, positive motivation might increase energy to perform a desired habit. The final way that goals and habits interact is when people infer their goals from observing their own habitual behavior, perhaps through a process similar to self-perception (Bem, 1972). Because people do not have conscious access to habit cuing, they may misattribute their own habits to their volition. This could happen for desired behaviors, when the action is 


\section{DEFINING HABIT IN PSYCHOLOGY}

attributed to intentions, as well as undesired behaviors, when the action is inferred to be due to the pull of temptations and suppressed desires. This model is illustrated in Figure 1:

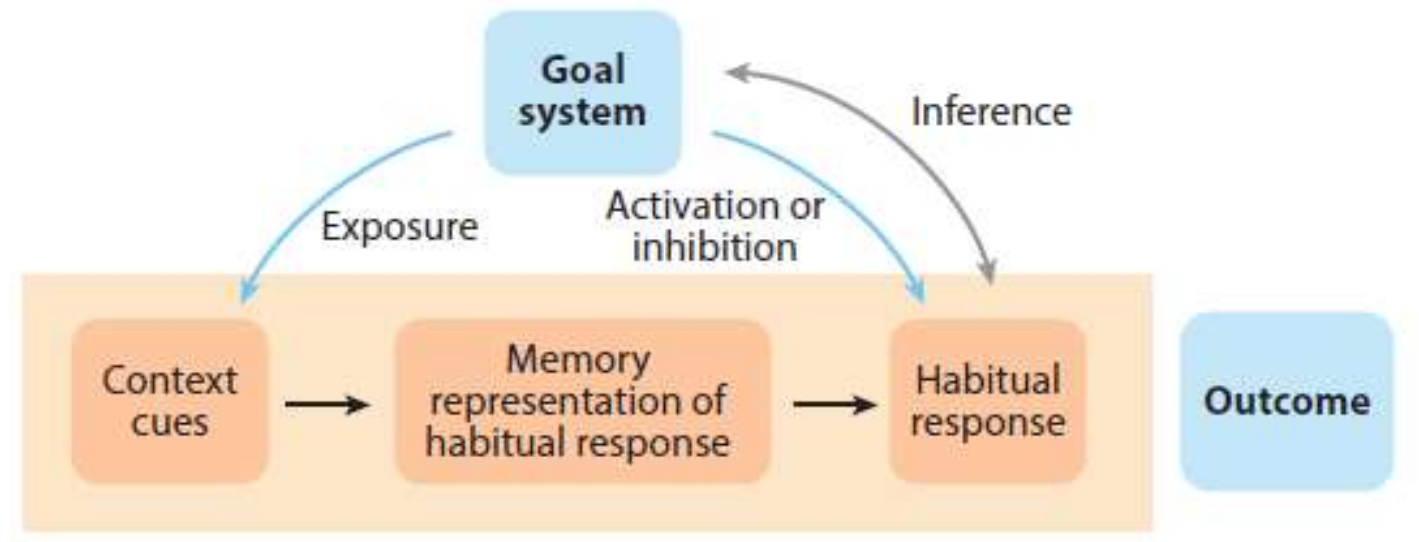

Figure 1. Goal-habit interface model from Wood and Rünger (2016). Goals interact with habit by: 1) facilitating consistent exposure to context cues (seen in the arrow connecting the goal system and context cues), 2) influencing whether mental representations of habitual behavior are acted on or inhibited (seen in the arrow going from the goal system to the habitual response), and 3) inferences of goals based on habitual behavior (seen in the bidirectional arrow connecting the goal system and the habitual response).

\section{Features of Habit Automaticity}

Recent accounts of habit point to automaticity as a key defining feature (Gardner, Abraham, Lally, \& de Bruijn, 2012; Orbell \& Verplanken, 2010). Most analyses do not, however, specify what is meant by "automaticity." Automaticity is a broad, multidimensional construct that includes several correlated but independent features (Bargh, 2013; Moors \& De Houwer, 2006). Automatic processes tend to be: goal-independent, in that they can function in the absence of, or even contrary to, intentions; unconscious, in that they can function without conscious awareness and may even be inaccessible to it; efficient, in that they do not require effortful attention or mental processing; fast; and perhaps most importantly for habits stimulus driven, in that they can be cued directly by perception of elements in the environment (Moors \& De Houwer, 2006).

Given that these various features of automaticity may not co-occur, the specific definition of automaticity adopted in any research usually depends on the topic of interest and 


\section{DEFINING HABIT IN PSYCHOLOGY}

the measure being used. Therefore, the most sensible approach for defining automaticity may be a polythetic one, whereby a process needs to show some but not all features of automaticity to be considered automatic to some degree. A classic definition that underlies many automaticity features is that automaticity involves single-step memory retrieval (Logan, 1988). Automaticity in this view means that, when a person perceives a stimulus, they directly retrieve the associated response from memory instead of effortfully calculating it. This echoes the idea of habit as direct retrieval of behavior in response to a cue, with no need for mediation by reflective processes.

Given the multifaceted nature of automaticity, it is useful to dissociate habit from other forms of single-step retrieval. For example, habits differ from the types of automaticity typically studied in social psychology, including concept priming and automatic goal pursuit a form of goal pursuit in which goals are activated and pursued without the need for conscious initiation and guidance. Automatic goal pursuit as well as concept priming are similar to habit in that they require little awareness or effortful attention (Aarts, 2007). However, these forms of automaticity differ from habit in that they assume spreading activation of semantic knowledge structures (Bargh, 2006). This stands in contrast to the direct cuing of a specific behavior in habit (Wood \& Rünger, 2016). For example, automatic goal pursuit assumes the activation of goals as hierarchical information structures in memory, which link goals to subordinate means for achieving them (Kruglanski et al., 2002). As such, the activation of a goal may result in diffuse activation of a variety of goal-related behaviors. Habits, on the other hand, involve a direct cue-behavior association, in which context cues a specific welllearned response.

\section{Context Dependence}

Any recurring feature of a performance context could, potentially, function as a habit cue. Although some studies have found that internal states such as mood may cue habitual 


\section{DEFINING HABIT IN PSYCHOLOGY}

behavior (Ji \& Wood, 2007), most research to date has focused on observable context cues, including physical location, time of day, and preceding actions in a sequence (see Botvinick \& Plaut, 2004; Ji \& Wood, 2007). Given the human ability to create abstract cognitive representations, it is possible that these function as context cues as well, so that a habitual response becomes associated not with a concrete sensory cue, but rather with an abstract representation such as "at work" or "at a bar." Congruent with this idea, naturalistic research on smoking finds that smoking episodes are correlated with such abstract antecedents as "socializing" (Shiffman et al., 1997). Yet such a pattern is also consistent with the possibility that, by repeatedly smoking in a variety of specific social situations, smokers have learned to associate the behavior with specific social contexts independently. Understanding the extent and conditions under which contexts generalize as cues to habits is an important direction for future habit research.

If context cues activate habitual responses, then a stable performance context should be important for habit formation. Repeating a behavior in a stable context allows for a consistent pairing of environmental cues with a behavior. However, repeating a behavior in irregular contexts would not produce the context reliance that underlies habits. Congruent with this hypothesis, context stability has shown incremental validity in predicting the frequency with which people perform various types of behavior, over and above measures of past frequency and intentions (Danner et al., 2008). Specifically, context stability moderates the relationship between the two latter variables and future behavior: For behaviors performed in varying contexts, intentions tend to predict future behavior better than past behavior. For behaviors performed in a stable context, however, past behavior is a stronger predictor (Ouellette \& Wood, 1998).

The direct cuing of habit was anticipated by William James's (1890) principle of ideomotor action. He argued that thinking about an action is to some extent inseparable from - 


\section{DEFINING HABIT IN PSYCHOLOGY}

and therefore likely to lead to - performance of that action (at least when people are not monitoring their responses and intending to act otherwise). Direct cuing is supported by research using reaction time measures to assess the strength of cognitive links between contexts and responses. For example, Danner et al. (2008) measured strength of bicycling habits from the speed with which participants reported whether they would use a bike to reach various local destinations. Response speed predicted bicycling frequency over the next four weeks. This was especially true for participants with stronger associations (i.e., who were faster to respond). Suggesting that these participants were acting on habit, their intentions to ride did not predict frequency of bicycling. Intentions did matter, however, for participants with weaker habit associations, who cycled more when they intended to do so (see also Neal et al., 2012).

A context acquires the capacity to activate a response as people learn that certain actions get rewarded in that context. Neural reactions to rewards forge ties between the context and response in memory (Wood \& Rünger, 2016). These associations drive even visual attention. Cues that have been associated with reward in the past draw attention automatically, even when they no longer predict reward and despite conscious attempts to ignore them (Anderson, 2016). Habit cues thus gain attention over other cues, potentially yielding a biased search for information search, so that people with strong habits tend to seek information about their habitual behavior but overlook information about alternatives (Verplanken, Aarts, \& van Knippenberg, 1997).

If habits depend on context, then shifts in contexts should attenuate habitual responding. Indeed, research on habit discontinuity supports this hypothesis (Aldrich, Montgomery, \& Wood, 2011; Thomas, Poortinga, \& Sautkina, 2016; Verplanken \& Roy, 2016; Verplanken, Walker, Davis, \& Jurasek, 2008; Wood, Tam, \& Witt, 2005). This literature uses changes in one's residence - to a new town, for example - as a natural 


\section{DEFINING HABIT IN PSYCHOLOGY}

experiment in context change. For example, among university employees who recently relocated, environmentally-concerned employees commuted less frequently by car compared with employees who were not environmentally concerned (Verplanken et al., 2008). Among employees who had not recently relocated, however, environmental concern did not predict use of car over public transport. It thus seems that the relocation disrupted transportation habits, giving employees more intentional control over their transportation behavior. Support for habit discontinuity comes not only from correlational designs, but also experiments (e.g., Verplanken \& Roy, 2016; see also Chapter 10 this volume). In both animals and humans, habits persist in the habitual context despite changes in reward value; in novel contexts, though, responses become sensitive to reward value, decreasing in frequency when no longer rewarding (Neal, Wood, Wu, \& Kurlander, 2011; Thrailkill \& Bouton, 2015).

\section{Goal Independence}

Context cues activate habitual behavior directly, without mediation through goals or intentions. Therefore, one indicator of whether a behavior is habitual is whether it persists even in the absence of goals. In animal models, a common way to assess habitual goal independence involves training rats to perform a behavior for food. Rats that received extensive (but not moderate) training in that behavior continued to perform it even after that food reward becomes aversive through pairing with a toxin (Adams, 1982; Dickinson, 1985). This suggests that habitual responses do not depend on representations of a desired outcome or goal, but instead are cued directly by context.

Research with human participants has similarly demonstrated that strong habits persist despite manipulations of outcome value. For example, persuasive appeals that changed preferences for soft drinks failed to change the drink choices of people with strong soft-drink habits (Itzchakov, Uziel, \& Wood, 2017). Changes in monetary incentives failed to change response habits in a game, so that people continued to make a habitual choice even though it 


\section{DEFINING HABIT IN PSYCHOLOGY}

was no longer rewarded (Gillan, Otto, Phelps, \& Daw, 2015). Eating a food to satiety did not deter participants from choosing that food when it was their habitual choice (Tricomi et al., 2009). People with strong habits to drink water in the dining commons or to bring their own water bottle were relatively unaffected by social norms to act otherwise (Mazar, Lieberman, Wood, \& Itzchakov, in preparation). Across these studies, a wide range of habitual behaviors were robust to fluctuations in otherwise potent motivators. Habits are a powerful source of behavioral resistance.

Humans create complex, prospective mental representations, with goals that vary in immediacy, abstractness, and accessibility to consciousness. Nonetheless, correlational research has demonstrated that habits persist relatively independently of a variety of goal types, including ones that are simpler vs more complex, abstract vs. concrete, and reported in personal terms vs. generic researcher-provided labels (Gardner, 2009; Ji \& Wood, 2007; Ouellette \& Wood, 1998; Verplanken, Aarts, Knippenberg, \& Moonen, 1998). Thus, variation in goals does not appear to explain habit persistence.

\section{Other Features of Automaticity}

Two defining features of habit are thus goal independence and cue dependence. Other aspects of automaticity are also useful for defining and measuring habit. First, habits are often inaccessible to conscious reflection. Although people may be aware of the outcome of habit from observing their own actions, they are normally not aware of its antecedents (i.e., triggering context cues) or the psychological mechanism that activates the response (the cuebehavior association).

The unconscious nature of habit naturally lends itself to misattribution. As an automatic process, the habit cue-behavior mechanism often goes unnoticed, and the mental content activated by habits may be misattributed to one's own goals and preferences (Loersch \& Payne, 2011). Therefore, habits may be susceptible to a discrepancy between perceived and 


\section{DEFINING HABIT IN PSYCHOLOGY}

actual antecedents of behavior, whereby diminishing intentional control is accompanied by increased perceived control. As already noted, strong habits were associated with an increased certainty of intentions, even though intentions did not predict behavior for these individuals (Ji \& Wood, 2007). In another study, participants with stronger running habits reported that their running was driven by their goals, although a cognitive association test revealed that goal priming did not activate running behaviors in mind (Neal et al., 2012). In addition, individual difference measures of self-control assess self-reports of people's ability to overcome distractions and effortfully pursue goals (see items such as "I am good at resisting temptation"; Tangney, Baumeister, \& Boone, 2004). However, people who score high on these measures often attain goals by acting on habit rather than acting on willpower and effortful resistance (Galla \& Duckworth, 2015). Therefore, it is possible that when people successfully self-regulate using habits, the obscurity of the process leads them to ascribe their success to more volitional sources.

\section{Habit Measurement}

Although most habit researchers agree on the theoretical definition of habits as automatic cue-response associations, operational definitions vary considerably. As a multifaceted construct, habit has been operationalized in various ways, with different research paradigms and tasks emphasizing different aspects of habit. In many circumstances, different habit measures yield congruent results and are highly correlated (e.g. Galla \& Duckworth, 2015). In some cases, however, they differ in important ways, with some predicting behavior more successfully than others (e.g. Labrecque \& Wood, 2015). Given this diversity, it is no surprise that researchers are showing a surge of interest in the question of how best to measure habits (Gardner, 2015; Gardner et al., 2012; Gardner \& Tang, 2013; Hagger, Rebar, Mullan, Lipp, \& Chatzisarantis, 2015).

\section{Self-Report Measures}




\section{DEFINING HABIT IN PSYCHOLOGY}

The most commonly used habit strength measures in social psychology are retrospective self-reports of frequency and experience of behavior. Behavior-frequency-andcontext-stability measures combine a measure of performance frequency (how often is the behavior performed) with a measure of context stability (i.e. how stable is the performance context; Ji \& Wood, 2007). This habit measure assumes that behaviors repeated often in a stable context are likely to become habitual through basic learning mechanisms. Habit strength is calculated as the product of the frequency and context stability terms, so that behaviors that are performed both often and in a stable context are considered habitual (see Wood \& Neal, 2009).

The foremost advantage of behavioral frequency and context stability measures is their substantial predictive power, arising in part from the strength of the past-future behavior association (Labrecque \& Wood, 2015). Indeed, Verplanken and Orbell (2003) found that across several studies, excluding behavior frequency scale items from an alternative measure of habit (the Self Report Habit Index) slightly reduced its predictive validity. In addition, behavioral-frequency-and-context-stability measures are context-sensitive, and therefore tap the cue-dependent nature of habits. However, behavioral frequency and context stability measures have been criticized because they rely on past behavior frequency, and potentially capture factors in addition to habit that might influence behavior (Ajzen, 2002). Moreover, these measures assess the conditions that are conducive to habit formation, rather than the strength of the cue-response association itself.

The Self Report Habit Index, in contrast, is a self-report measure that directly assesses perceptions of performance repetition, automaticity, and self-identification with an action (Verplanken \& Orbell, 2003). A subset of items from this scale - the Self Report Behavioral Automaticity Index - includes only the four Self Report Habit Index items that specifically target automaticity (Gardner et al., 2012). Both measures have demonstrated reliability and 


\section{DEFINING HABIT IN PSYCHOLOGY}

predictive validity, with the Self Report Habit Index predicting behavior somewhat better than the Self Report Behavioral Automaticity Index (Verplanken \& Orbell, 2003; Gardner et al., 2012). By focusing on automaticity rather than behavioral frequency, the Self Report Behavioral Automaticity index (and to a lesser degree, the Self Report Habit Index) avoids the conflation of other factors inherent in measuring the past-future behavior association. The main limitation of both measures is that they require participants to self-report on automaticity - a construct that, by its very definition, may resist conscious reflection (Hagger et al., 2015). As Sniehotta and Presseau (2012, p. 139) note: “a self-report likely reflects an inference about one's behavior based on the consequences of the habit...rather than on a report of the habit itself." Another problem is that these scales were originally created without specifying a context (Verplanken \& Orbell, 2003), and subsequent research has continued in this vein, failing to measure cue dependence (see Gardner, 2015). As such, the scales often do not isolate the context-dependent automaticity of habit. Instead, they may capture the effect of other automatic processes as well, such as the feelings of fluency that come from automated goal pursuit (Labrecque, Lee, \& Wood, in preparation).

To identify context cues, respondents could self-report everyday triggers to their habitual behavior (Gardner, 2015). Using this approach, Neal et al. (2012) solicited the locations in which participants typically ran (if they ever did), and individually tailored a reaction time task with this information. However, people often have only limited awareness of the cues that elicit their habitual behavior. Self-reported cues may reflect lay theories of behavior just as much as they reflect actual determinants. In evidence, both smokers and socalled emotional eaters tended to attribute past smoking and eating episodes to negative affect, even when researchers did not find that affect was associated with these behaviors (Shiffman et al., 1997; Adriaanse et al., 2016). Thus, further research is needed on how to identify the context cues that trigger habits. 


\section{DEFINING HABIT IN PSYCHOLOGY}

\section{Behavioral, Implicit, and Ecological Assessment Methods}

Given the questions we raised about the validity of self-report methods, the most promising directions for future habit measurement may lie in alternative measures that assess

(a) behavioral sensitivity to changes in goals and performance context or (b) implicit cognitive associations in ecologically valid contexts.

Behavioral sensitivity is represented in the basic pattern that strong habits persist even when that behavior no longer achieves a desired goal. In addition, such responses should become goal-sensitive in novel contexts, where triggering cues are removed.

Reward devaluation paradigms assess goal independence by experimentally manipulating the value of a behavior's outcome. In these paradigms, participants first learn to perform a behavior to obtain a desirable outcome. The outcome is then devalued, either by reducing the value of the outcome, or the contingency between the behavior and the outcome. For example, in one study, participants were trained to press a button for a food and then ate that food to satiety (Tricomi et al., 2009). Participants who received extensive training (but not moderate training) kept choosing the same food, despite being sated.

The advantage of outcome devaluation paradigms is that they successfully dissociate goal dependent from goal independent (habitual) repeated behaviors. However, a limitation of these paradigms is the assumption that behavior is either habitual or goal-directed, so that weak goal-directed responding implies strong habitual responding (Watson \& de Wit, 2018; see also Chapters 3 and 17 this volume). Behavior that is goal independent need not necessarily be context dependent (Foerde, 2018). Indeed, outcome insensitivity in reward devaluation paradigms is associated more strongly with deficits in goal-directed control rather than a surplus in habitual control (see Watson \& de Wit, 2018).

A possible solution may be paradigms that combine reward devaluation and context change, so that a behavior is considered habitual if it is insensitive to outcome devaluation in 


\section{DEFINING HABIT IN PSYCHOLOGY}

the habitual context, but sensitive to outcome devaluation in a novel context (for example, see Thrailkill \& Bouton, 2015). The advantage of these paradigms is that habits are assessed not only from the absence of goal dependence but also by the presence of context dependence. For example, Neal et al. (2011) gave either fresh or stale popcorn to movie goers in a cinema (a habitual context) or a conference room (a novel context). In the cinema, participants with strong popcorn-eating habits ate similar amounts of fresh and stale popcorn, despite their explicit dislike for the stale popcorn. Therefore, their behavior was goal-independent. In the conference room setting, however, participants with both strong and weak habits acted in line with their goals and ate more fresh popcorn than stale.

Implicit measures of habit strength. Implicit measures can be broadly defined as measures in which the focal outcome is primarily produced by automatic processes (De Houwer, Teige-Mocigemba, Spruyt, \& Moors, 2009). Such measures typically use reaction time as a marker of cognitive accessibility or the strength of cognitive associations. For example, Neal et al. (2012) asked runners for one-word descriptions of their goals for running (e.g. "health") as well as the context in which they usually ran (e.g. "park"). Participants then were primed with a word and indicated whether a second, subsequent letter string was a word or a nonword. As predicted, priming with context cues facilitated (speeded) recognition of running words for participants with strong (but not weak) running habits. Moreover, goals did not facilitate response to running words in strongly habitual runners, attesting to the goalindependent nature of habits.

To the best of our knowledge, two studies to date have used reaction time habit strength measures as predictors. The first (Danner et al., 2008), found that a reaction time habit measure predicted future bicycle riding frequency (see Context Dependence section for more details). In a second study, Labrecque et al.'s (unpublished) participants learned a sequential computerized sushi making task. To assess habit strength, participants saw a 


\section{DEFINING HABIT IN PSYCHOLOGY}

random step from the sequence and responded as quickly as possible with the appropriate following step. Faster responding indicated greater habit strength. In addition to this implicit measure, participants reported habit strength on a self-report measure (the Self Report Behavioral Automaticity Index; Gardner et al., 2012). In comparisons between the two measures, only reaction time, and not self-reported automaticity, predicted whether habits persisted despite changes in intentions. Furthermore, the reaction time and self-report measures were not correlated, suggesting the measures were tapping different constructs. All in all, the insights gained from this study point to the promise of measures that directly tap the strength of mental associations.

Ecological assessments. Ecological momentary assessment is a relatively unexplored but promising direction for implicit measures. Participants are prompted, often with mobile devices, to complete brief measures several times a day while going through their daily routine (Stone, Shiffman, \& DeVries, 1999; Wood et al., 2002). Ecological momentary assessment can include implicit measures along with self-report ratings. The potential is to evaluate context triggers while participants are in a habitual setting. Although some researchers have suggested that implicit measures are impractical in nonlaboratory settings (Gardner, 2015), a number of studies have already reliably administered implicit measures online or on mobile devices (see Marhe, Waters, van de Wetering, \& Franken, 2013; Sabin, Marini, \& Nosek, 2012; Waters, Marhe, \& Franken, 2012). Administering implicit measures in ecological contexts, although technically demanding to implement, offers an exciting new pathway for habit research.

\section{Conclusions}

It seems that lay perceptions of habit are quite close to scientific understanding. People understand that habitual behavior may be unintentional or even uncontrollable. As such, they recognize one of the key characteristics of habit - goal independence. Whether 


\section{DEFINING HABIT IN PSYCHOLOGY}

people intuitively understand that habits are directly cued by contexts remains to be seen. Although people may have a fairly accurate lay understanding of habit, they are not always able to distinguish habitual from goal-directed behavior. The inaccessibility of the automatic habit cuing mechanism means that people tend to misinterpret habitual behavior as arising from motivational processes, whether conscious intentions in the case of desirable behaviors, or appetitive impulses in the case of undesirable habits.

In research, a prominent issue is the gap between theoretical and operational definitions of habit. Despite increased interest in habit measurement, operational definitions of habit still lag behind theoretical understanding. An overwhelming majority of studies to date use retrospective self-reports to assess habit strength, and many do not assess context dependence or repetition history - primary distinguishing features of habit automaticity. Although there is yet no accepted "gold standard" criterion against which to compare habit measures, habit research to date suggests two main predictions which should apply for valid habit measures. First, habits should be insensitive to changes to the behavior's expected outcome. Second, habits should be sensitive to differences in context.

Two promising methods for future habit research are implicit measures and ecologically-assessed behavioral sensitivity to changes in goals and context. Implicit measures afford considerable construct validity in that they measure cognitive associations directly instead of inferring them from behavior. Ecological momentary assessment can bolster implicit measures by assessing naturalistic context priming. Behavioral criteria of sensitivity to changes in goals and context improve on mere frequency measures as benchmarks for distinguishing habitual responding from non-habitual responding. By integrating self-report, implicit, and behavioral measures, researchers can produce strong, valid conclusions about the way habits shape behavior. 


\section{DEFINING HABIT IN PSYCHOLOGY}

\section{References}

Aarts, H. (2007). Health and goal-directed behavior: The nonconscious regulation and motivation of goals and their pursuit. Health Psychology Review, 1(1), 53-82. https://doi.org/10.1080/17437190701485852

Adriaanse, M. A., Prinsen, S., de Witt Huberts, J. C., de Ridder, D. T. D., \& Evers, C. (2016). 'I ate too much so I must have been sad': Emotions as a confabulated reason for overeating. Appetite, 103, 318-323. https://doi.org/10.1016/j.appet.2016.04.028

Adams, C. D. (1982). Variations in the sensitivity of instrumental responding to reinforcer devaluation. The Quarterly Journal of Experimental Psychology Section B, 34(2), 77-98. https://doi.org/10.1080/14640748208400878Ajzen, I. (2002). Residual Effects of Past on Later Behavior: Habituation and Reasoned Action Perspectives. Personality and Social Psychology Review, 6(2), 107-122. https://doi.org/10.1207/S15327957PSPR0602_02

Aldrich, J. H., Montgomery, J. M., \& Wood, W. (2011). Turnout as a habit. Political Behavior, 33(4), 535-563. https://doi.org/10.1007/s11109-010-9148-3

Anderson, B. A. (2016). The attention habit: How reward learning shapes attentional selection. Annals of the New York Academy of Sciences, 1369, 24-39. doi:10.1111/nyas.12957

Bargh, J. A. (2006). What have we been priming all these years? On the development, mechanisms, and ecology of nonconscious social behavior. European Journal of Social Psychology, 36(2), 147-168. https://doi.org/10.1002/ejsp.336

Bargh, J. A. (2013). Social psychology and the unconscious: The automaticity of higher mental processes. Psychology Press.

Bem, D. J. (1972). Self-Perception Theory. Advances in Experimental Social Psychology, 6, 1-62. https://doi.org/10.1016/S0065-2601(08)60024-6 


\section{DEFINING HABIT IN PSYCHOLOGY}

Botvinick, M., \& Plaut, D. C. (2004). Doing without schema hierarchies: A recurrent connectionist approach to normal and impaired routine sequential action. Psychological Review, 111, 395429.

Danner, U. N., Aarts, H., \& de Vries, N. K. (2008). Habit vs. intention in the prediction of future behaviour: The role of frequency, context stability and mental accessibility of past behaviour. British Journal of Social Psychology, 47(2), 245-265. https://doi.org/10.1348/014466607X230876

De Houwer, J., Teige-Mocigemba, S., Spruyt, A., \& Moors, A. (2009). Implicit measures: A normative analysis and review. Psychological Bulletin, 135(3), 347-368. http://dx.doi.org.libproxy1.usc.edu/10.1037/a0014211

de Wit, S., \& Dickinson, A. (2009). Associative theories of goal-directed behaviour: a case for animal-human translational models. Psychological Research PRPF, 73(4), 463-476. https://doi.org/10.1007/s00426-009-0230-6Dickinson, A. (1985). Actions and habits: the development of behavioural autonomy. Phil. Trans. R. Soc. Lond. B, 308(1135), 67-78. https://doi.org/10.1098/rstb.1985.0010

Evans, J. S. B., \& Stanovich, K. E. (2013). Dual-process theories of higher cognition: Advancing the debate. Perspectives on Psychological Science, 8(3), 223-241.

Fishbein, M., \& Ajzen, I. (1975). Belief, attitude, intention and behavior: An introduction to theory and research. Reading, MA, USA: Addison-Wesley.

Fishbein, M., \& Ajzen, I. (2011). Predicting and changing behavior: The reasoned action approach. Taylor \& Francis. New York, NY, USA: Psychology Press.

Foerde, K. (2018). What are habits and do they depend on the striatum? A view from the study of neuropsychological populations. Current Opinion in Behavioral Sciences, 20, 17-24. https://doi.org/10.1016/j.cobeha.2017.08.011 


\section{DEFINING HABIT IN PSYCHOLOGY}

Galla, B. M., \& Duckworth, A. L. (2015). More than resisting temptation: Beneficial habits mediate the relationship between self-control and positive life outcomes. Journal of Personality and Social Psychology, 109(3), 508-525. https://doi.org/10.1037/pspp0000026

Gardner, B. (2009). Modelling motivation and habit in stable travel mode contexts. Transportation Research Part F: Traffic Psychology and Behaviour, 12(1), 68-76.

https://doi.org/10.1016/j.trf.2008.08.001

Gardner, B. (2015). A review and analysis of the use of 'habit' in understanding, predicting and influencing health-related behaviour. Health Psychology Review, 9(3), 277-295.

Gardner, B., Abraham, C., Lally, P., \& de Bruijn, G.-J. (2012). Towards parsimony in habit measurement: Testing the convergent and predictive validity of an automaticity subscale of the Self-Report Habit Index. The International Journal of Behavioral Nutrition and Physical Activity, 9, 102. https://doi.org/10.1186/1479-5868-9-102

Gardner, B., \& Tang, V. (2014), Reflecting on non-reflective action: An exploratory think-aloud study of self-report habit measures. British Journal of Health Psychology, 19, 258-273. https://doi.org/10.1111/bjhp.12060

Gershman, S. J., Gerstenberg, T., Baker, C. L., \& Cushman, F. A. (2016). Plans, habits, and theory of mind. PloS one, 11(9), e0162246. https://doi.org/10.1371/journal.pone.0162246

Gillan, C. M., Otto, A. R., Phelps, E. A., \& Daw, N. D. (2015). Model-based learning protects against forming habits. Cognitive, Affective \& Behavioral Neuroscience, 15(3), 523-536. https://doi.org/10.3758/s13415-015-0347-6

Hagger, M. S., Rebar, A. L., Mullan, B., Lipp, O. V., \& Chatzisarantis, N. L. D. (2015). The subjective experience of habit captured by self-report indexes may lead to inaccuracies in the measurement of habitual action. Health Psychology Review, 9(3), 296-302.

https://doi.org/10.1080/17437199.2014.959728 


\section{DEFINING HABIT IN PSYCHOLOGY}

Hull, C. L. (1943). Principles of behavior: an introduction to behavior theory. Oxford, England: Appleton-Century.

Itzchakov, G., Uziel, L., \& Wood, W. (2018). When attitudes and habits don't correspond: Selfcontrol depletion increases persuasion but not behavior. Journal of Experimental Social Psychology, 75, 1-10. https://doi.org/10.1016/j.jesp.2017.10.011

James, W. (1890). The principles of psychology (Vol. 2). New York: Henry Holt and Company.

James, W. (1916/1983). Talks to teachers on psychology and to students on some of life's ideals. Cambridge, MA: Harvard University Press.

Ji, M. F., \& Wood, W. (2007). Purchase and Consumption Habits: Not Necessarily What You Intend. Journal of Consumer Psychology (Lawrence Erlbaum Associates), 17(4), 261-276. https://doi.org/10.1080/10577400701542403

Knowlton, B. J., \& Patterson, T. K. (2016). Habit Formation and the Striatum. In Behavioral Neuroscience of Learning and Memory (pp. 275-295). Springer, Cham. https://doi.org/10.1007/7854_2016_451

Kruglanski, A. W., Shah, J. Y., Fishbach, A., Friedman, R., Chun, W. Y., \& Sleeth-Keppler, D. (2002). A theory of goal systems. In M. P. Zanna (Ed.), Advances in Experimental Social Psychology (Vol. 34, pp. 331-378). Academic Press. Retrieved from http://www.sciencedirect.com/science/article/pii/S0065260102800089

Labrecque, J. S., Lee, K., \& Wood, W. (2018). Overthinking habit. Manuscript in preparation. Labrecque, J. S., Wood, W., Neal, D. T., \& Harrington, N. (2016). Habit slips: when consumers unintentionally resist new products. Journal of the Academy of Marketing Science, 1-15. https://doi.org/10.1007/s11747-016-0482-9

Loersch, C., \& Payne, B. K. (2011). The Situated Inference Model: An Integrative Account of the Effects of Primes on Perception, Behavior, and Motivation. Perspectives on Psychological Science, 6(3), 234-252. https://doi.org/10.1177/1745691611406921 


\section{DEFINING HABIT IN PSYCHOLOGY}

Logan, G. D. (1988). Toward an instance theory of automatization. Psychological Review, 95(4), 492-527. http://dx.doi.org.libproxy1.usc.edu/10.1037/0033-295X.95.4.492

Mantzari, E., Vogt, F., Shemilt, I., Wei, Y., Higgins, J. P. T., \& Marteau, T. M. (2015). Personal financial incentives for changing habitual health-related behaviors: A systematic review and meta-analysis. Preventive Medicine, 75, 75-85. https://doi.org/10.1016/j.ypmed.2015.03.001

Marhe, R., Waters, A. J., van de Wetering, B. J. M., \& Franken, I. H. A. (2013). Implicit and explicit drug-related cognitions during detoxification treatment are associated with drug relapse: An ecological momentary assessment study. Journal of Consulting and Clinical Psychology, 81(1), 1-12. http://dx.doi.org/10.1037/a0030754

Mazar, A. S., Lieberman, A., Wood, W., \& Itzchakov, G. Manuscript in preparation.

Miller, G. A., Galanter, E., \& Pribram, K. H. (1960). Plans and the structure of behavior. New York, NY: Holt.

Moors, A., \& De Houwer, J. (2006). Automaticity: A Theoretical and Conceptual Analysis. Psychological Bulletin, 132(2), 297-326. http://dx.doi.org.libproxy1.usc.edu/10.1037/0033$\underline{2909.132 .2 .297}$

Neal, D. T., Wood, W., \& Drolet, A. (2013). How do people adhere to goals when willpower is low? The profits (and pitfalls) of strong habits. Journal of Personality and Social Psychology, 104(6), 959-975. https://doi.org/10.1037/a0032626

Neal, D. T., Wood, W., Labrecque, J. S., \& Lally, P. (2012). How do habits guide behavior? Perceived and actual triggers of habits in daily life. Journal of Experimental Social Psychology, 48(2), 492-498. https://doi.org/10.1016/j.jesp.2011.10.011

Neal, D. T., Wood, W., Wu, M., \& Kurlander, D. (2011). The Pull of the Past When Do Habits Persist Despite Conflict With Motives? Personality and Social Psychology Bulletin, 37(11), 1428-1437. https://doi.org/10.1177/0146167211419863 


\section{DEFINING HABIT IN PSYCHOLOGY}

Orbell, S., \& Verplanken, B. (2010). The automatic component of habit in health behavior: Habit as cue-contingent automaticity. Health Psychology, 29(4), 374-383. https://doi.org/10.1037/a0019596

Orbell, S., \& Verplanken, B. (2015). The strength of habit. Health Psychology Review, 9(3), 311317. https://doi.org/10.1080/17437199.2014.992031

Ouellette, J. A., \& Wood, W. (1998). Habit and intention in everyday life: The multiple processes by which past behavior predicts future behavior. Psychological Bulletin, 124(1), 54-74. https://doi.org/10.1037/0033-2909.124.1.54

Phillips, L. A., \& Gardner, B. (2016). Habitual exercise instigation (vs. execution) predicts healthy adults' exercise frequency. Health Psychology, 35(1), 69-77. http://dx.doi.org.libproxy1.usc.edu/10.1037/hea0000249

Sabin, J. A., Marini, M., \& Nosek, B. A. (2012). Implicit and Explicit Anti-Fat Bias among a Large Sample of Medical Doctors by BMI, Race/Ethnicity and Gender. PLOS ONE, 7(11), e48448. https://doi.org/10.1371/journal.pone.0048448

Sherman, J. W., Gawronski, B., \& Trope, Y. (Eds.). (2014). Dual-process theories of the social mind. New York, NY, USA: Guilford Press.

Shiffman, S., Hufford, M., Hickcox, M., Paty, J. A., Gnys, M., \& Kassel, J. D. (1997). Remember that? A comparison of real-time versus retrospective recall of smoking lapses. Journal of consulting and clinical psychology, 65(2), 292.

Shiffrin, R. M., \& Schneider, W. (1977). Controlled and automatic human information processing: II. Perceptual learning, automatic attending and a general theory. Psychological review, 84(2), 127.

Skinner, B. F. (1938). The behavior of organisms: an experimental analysis. New York, NY, USA: Appleton-Century. 


\section{DEFINING HABIT IN PSYCHOLOGY}

Sniehotta, F. F., \& Presseau, J. (2012). The Habitual Use of the Self-report Habit Index. Annals of Behavioral Medicine; New York, 43(1), 139-140; author reply 141-2. http://dx.doi.org.libproxy2.usc.edu/10.1007/s12160-011-9305-x

Squire, L. R., \& Zola-Morgan, S. (1991). The medial temporal lobe memory system. Science, 253(5026), 1380-1386. https://doi.org/10.1126/science.1896849

Stone, A. A., Shiffman, S. S., \& DeVries, M. W. (1999). Ecological momentary assessment. In D. Kahneman, E. Diener, \& N. Schwarz (Eds.), Well-being: The foundations of hedonic psychology (pp. 26-39). New York, NY, US: Russell Sage Foundation.

Tangney, J. P., Baumeister, R. F., \& Boone, A. L. (2004). High Self-Control Predicts Good Adjustment, Less Pathology, Better Grades, and Interpersonal Success. Journal of Personality, 72(2), 271-324. https://doi.org/10.1111/j.0022-3506.2004.00263.x

Thomas, G. O., Poortinga, W., \& Sautkina, E. (2016). Habit Discontinuity, Self-Activation, and the Diminishing Influence of Context Change: Evidence from the UK Understanding Society Survey. PLOS ONE, 11(4), e0153490. https://doi.org/10.1371/journal.pone.0153490

Thorndike, E. L. (1898). Animal intelligence: an experimental study of the associative processes in animals. The Psychological Review: Monograph Supplements, 2(4), i.

Thrailkill, E. A., \& Bouton, M. E. (2015). Contextual control of instrumental actions and habits. Journal of Experimental Psychology: Animal Learning and Cognition, 41(1), 69-80. http://dx.doi.org.libproxy1.usc.edu/10.1037/xan0000045

Tolman, E. C. (1948). Cognitive maps in rats and men. Psychological review, 55(4), 189.

Triandis, H. C. (1977). Interpersonal Behavior. Pacific Grove, CA, USA: Brooks-Cole Publishing. Triandis, H. C. (1980). Values, attitudes, and interpersonal behavior. Nebraska Symposium on Motivation, 27, 195-259 


\section{DEFINING HABIT IN PSYCHOLOGY}

Tricomi, E., Balleine, B. W., \& O’Doherty, J. P. (2009). A specific role for posterior dorsolateral striatum in human habit learning. European Journal of Neuroscience, 29(11), 2225-2232. https://doi.org/10.1111/j.1460-9568.2009.06796.x

Verplanken, B., Aarts, H., \& van Knippenberg, A., (1997). Habit, information acquisition, and the process of making travel mode choices. European Journal of Social Psychology, 27(5), 539560. https://doi.org/10.1002/(SICI)1099-0992(199709/10)27:5<539::AID-

\section{$\underline{\text { EJSP831>3.0.CO;2-A }}$}

Verplanken, B., Aarts, H., van Knippenberg, A., \& Moonen, A. (1998). Habit versus planned behavior: A field experiment. British Journal of Social Psychology, 37 (1), 111-128. https://doi.org/10.1111/j.2044-8309.1998.tb01160.x

Verplanken, B., \& Orbell, S. (2003). Reflections on past behavior: A self-report index of habit strength. Journal of Applied Social Psychology, 33(6), 1313-1330. https://doi.org/10.1111/j.1559-1816.2003.tb01951.x

Verplanken, B., \& Roy, D. (2016). Empowering interventions to promote sustainable lifestyles: Testing the habit discontinuity hypothesis in a field experiment. Journal of Environmental Psychology, 45, 127-134. https://doi.org/10.1016/j.jenvp.2015.11.008

Verplanken, B., Walker, I., Davis, A., \& Jurasek, M. (2008). Context change and travel mode choice: Combining the habit discontinuity and self-activation hypotheses. Journal of Environmental Psychology, 28(2), 121-127. https://doi.org/10.1016/j.jenvp.2007.10.005

Waters, A. J., Marhe, R., \& Franken, I. H. A. (2012). Attentional bias to drug cues is elevated before and during temptations to use heroin and cocaine. Psychopharmacology, 219(3), 909-921. http://dx.doi.org/10.1007/s00213-011-2424-z

Watson, P., \& de Wit, S. (2018). Current limits of experimental research into habits and future directions. Current Opinion in Behavioral Sciences, 20, 33-39.

https://doi.org/10.1016/j.cobeha.2017.09.012 


\section{DEFINING HABIT IN PSYCHOLOGY}

Wood, W., \& Neal, D. T. (2009). The habitual consumer. Journal of Consumer Psychology 19, 579592.

Wood, W., \& Neal, D. T. (2016). Healthy through habit: Interventions for initiating \& maintaining health behavior change. Behavioral Science \& Policy, 2(1), 71-83.

https://doi/org/10.1353/bsp.2016.0008

Wood, W., \& Rünger, D. (2016). Psychology of Habit. Annual Review of Psychology, 67(1), 289314. https://doi.org/10.1146/annurev-psych-122414-033417

Wood, W., Tam, L., \& Witt, M. G. (2005). Changing circumstances, disrupting habits. Journal of Personality and Social Psychology, 88(6), 918-933.

http://dx.doi.org.libproxy1.usc.edu/10.1037/0022-3514.88.6.918

Wood, W., Quinn, J. M., \& Kashy, D. A. (2002). Habits in everyday life: Thought, emotion, and action. Journal of Personality and Social Psychology, 83(6), 1281-1297. https://doi.org/10.1037/0022-3514.83.6.1281

Yin, H. H., \& Knowlton, B. J. (2006). The role of the basal ganglia in habit formation. Nature Reviews Neuroscience, 7(6), 464-476. https://doi.org/10.1038/nrn1919 